\title{
Effects of Heat Treatment Temperature on Microstructure and Mechanical Properties of M2 High-Speed Steel Selective Laser Melting Samples
}

\author{
Huan Ding; Xiang Xiong; Rutie Liu; Jie Xu
}

Abstract: At different heat treatment temperatures, the hardness and flexural strength of M2 high-speed steel selective laser melting (SLM) parts show mixed trends. When the heat treatment temperature is $260^{\circ} \mathrm{C}$, the hardness and flexural strength of the M2 high-speed steel SLM part are decreased, but the hardness difference between the upper and lower surfaces of the M2 high-speed steel SLM part is also reduced. When the heat treatment temperature is $560^{\circ} \mathrm{C}$, the hardness and flexural strength of the M2 high-speed steel SLM part are almost close to that of the original M2 high-speed steel SLM part, and the performance gradient in the sample is improved, and the overall structure is uniform. When the subsequent heat treatment temperature is $860{ }^{\circ} \mathrm{C}$, the hardness of the SLM parts reaches a minimum, with an average value of $24 \mathrm{HRC}$. However, the flexural strength exceeds that of the original SLM parts. Moreover, the microstructure of the sample is uniform, which significantly improves the anisotropy of performance.

Keywords: high-speed steel (HSS); selective laser melting (SLM); annealing; microstructure; hardness; flexural strength

\section{Introduction}

Additive manufacturing (AM) has become the most popular manufacturing method in recent years. We can expect that AM technology will play an important role in manufacturing complex shapes in the future. Besides, many scientific publications in recent years have emphasized the primary importance of AM technology in this century. In addition, AM technology is fundamentally different from traditional manufacture or subtractive manufacturing processes. One of the most significant differences is that the AM technology does not require the use of molds. Traditional subtractive manufacturing processes always need molds to form parts. In this regard, it cannot directly create complex parts and relies on post-processing - this type of manufacturing wastes too much materials. In contrast, additive manufacturing without any mold is required. It can directly form parts of any shape. 
Selective laser melting (SLM) technology is one of the new 3D printing technologies in AM. Compared to laser engineered net shaping (LENS) technology, selective laser sintering (SLS) technology, and electron beam selective melting (EBSM) technologies, SLM technology uses relatively simple equipment, and the laser can completely melt metal materials. At the same time, the molten metal cools so quickly that extremely fine grain structures are eventually formed in the metal parts. This technique can be applied to most metallic materials [1].

In the past few decades, 316L stainless steel, H13 tool steel, titanium alloy, magnesium alloy, and aluminum alloy are the primary alloy materials prepared and studied by SLM technology [2]. Wang examined the surface roughness, dimensional accuracy, and physical and mechanical properties of 316L stainless steel manufactured by SLM technology [3]. Mertens studied the phase composition and tensile properties of H13 tool steel prepared by SLM at different substrate temperatures [4]. Hoeges studied the separation of the differences between 316L stainless steel powder made by SLM, 316L stainless steel powder prepared by aerosol, and 316L stainless steel powder prepared by water atomization under the same parameters [5]. Francesco made aluminum alloy through the SLM process and studied the effects of the heat treatment processes on the microstructure and mechanical properties of the alloy [6]. Foret et al. [7] studied the effects of the oxygen content and powder oxygen content in the forming cavity of the SLM machine on Al-SiMg alloy during operation. Frisk et al. [8] prepared Ti-6Al-4V alloy by combining the hot isostatic pressing technology and SLM technology. Wang et al. [9] studied the influence of process parameters on SLM titanium alloy. M2 high-speed steel (HSS) is one of the earliest HSS materials used in the world and has a wide range of uses. The traditional preparation method of M2 HSS is fused casting. The disadvantage is that the carbides in the structure are thick and uneven, and it is easy to segregate the components, which affects the mechanical properties of the material [10-12]. As a new special powder metallurgy preparation method, SLM technology not only has the advantages of the traditional powder metallurgy methods, such as uniform structure and high density [13-15], but also can form complex and precise parts without using any mold. Due to the complex composition of M2 HSS material, there have been few studies on the preparation of M2 HSS by SLM. Therefore, this research adopts the SLM technique to produce M2 HSS alloy and studies the effects of heat treatment temperature on the microstructure and mechanical properties. The experimental results will be useful for preparing high-performance HSS materials. 
However, many studies have shown insufficient results. Due to the high content of carbon and other alloying elements (high cold-crack tendency), the HSS materials are considered difficult to process by SLM. Besides, the HSS materials exhibit complex processability due to phase transformation, such as martensitic transformation and precipitation of solid carbides. It is associated with the change of a specific volume during the phase transformation. It may also cause additional stresses, thereby supporting the formation and propagation of cracks and the distortion of the specimen [16]. Through the author's previous work [17], i.e., the studies of the basic microstructure and mechanical properties of M2 HSS based on SLM technology, it shows that with the increase of the substrate temperature, the microstructure of HSS becomes more uniform, the columnar crystals grow from single direction to multi-direction, the carbide content increases, and the solid solution of the alloy elements increases. All these results indicate that heat treatment should be performed on the as-printed parts to make them homogeneous. Therefore, the primary purpose of this work is to investigate the effects of heat treatment on the microstructure and mechanical properties of M2 HSS as-print parts.

\section{Materials and Method}

In this study, the AM samples were prepared by the FS-271M system (Farsoon Tech, China). The SLM machine is equipped with a $500 \mathrm{~W}$ Gaussian beam fiber laser. The laser beam is $80 \mu \mathrm{m}$ in diameter. M2 HSS powder was supplied by AMC Powders (China). The composition of the powder is shown in Table 1 , the bulk density of the powder is $4.16 \mathrm{~g} / \mathrm{cm}^{3}$, and the morphology and particle size distribution of the gas atomized powder is shown in Fig.1.

Table 1 Nominal chemical composition of gas atomized HSS powder

\begin{tabular}{cccccccc}
\hline Element & $\mathrm{C}$ & $\mathrm{O}$ & $\mathrm{W}$ & $\mathrm{Mo}$ & $\mathrm{V}$ & $\mathrm{Cr}$ & $\mathrm{Fe}$ \\
\hline wt.\% & 0.82 & 0.03 & 6.12 & 4.65 & 1.95 & 4.55 & Remain \\
\hline
\end{tabular}

The powder was sieved with a 250-mesh sieve to remove large powder particles and ensure that the particle size was less than $58 \mu \mathrm{m}$. After sieving and drying, the powder was loaded into a powder drum of the SLM machine. The printing substrate was sandblasted to increase roughness to prevent the bottom powder from sliding during printing. After the substrate temperature raised to the set temperature, the leveling process was carried out. Finally, the SLM experiment was 
started. After the molding process, the AM samples and the substrates were separated by a wire cutting method to obtain SLM HSS samples. The heat treatment temperatures were set to 260, 560, and $860{ }^{\circ} \mathrm{C}$, respectively. SLM printing parameters are listed in Table 2. Three samples were printed for each heat treatment temperature and the average value of the three samples was calculated.
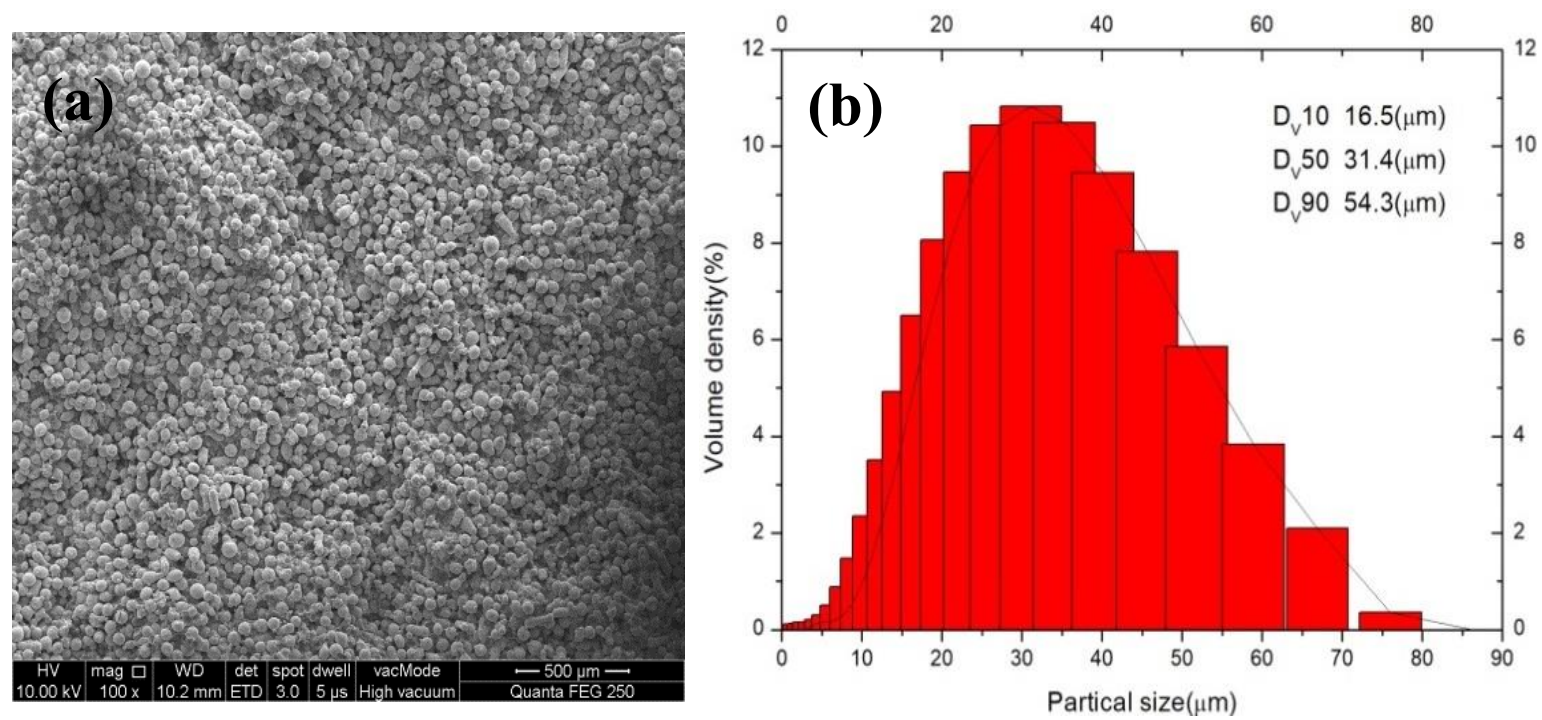

Fig. 1 (a) Shape of powder, (b) Size of powder

To observe the sample surfaces, a Quanta 3D dual beam field emission gun (FEG) focused ion beam (FIB) scanning electron microscope (SEM/FIB, Thermo Fisher Scientific, USA) was used before and after the heat treatment. Moreover, X-ray diffraction (XRD) was conducted by a D500 X-Ray Diffractometer (Simens, Germany) within a range of $2 \theta$ between $10^{\circ}$ and $90^{\circ}$ at room temperature. For characterizing the mechanical properties of the part, the Instron 3369 LOW FORCE UNIVERSAL TESTING SYSTEMS and HBRV-187.5 broad hardness tester were used to measure the flexural strength and hardness. 
Table 2 SLM printed parameters and heat treatment temperatures

\begin{tabular}{ccccc}
\hline Heat treatment temperature & $\begin{array}{c}\text { Laser } \\
\text { Power } \\
\left({ }^{\circ} \mathrm{C}\right)\end{array}$ & $\begin{array}{c}\text { Laser Scanning } \\
\text { velocity } \\
\left(\mathrm{mm} \cdot \mathrm{s}^{-1}\right)\end{array}$ & $\begin{array}{c}\text { Hatch } \\
\text { Spacing } \\
(\mathrm{mm})\end{array}$ & $\begin{array}{c}\text { Thickness } \\
(\mathrm{mm})\end{array}$ \\
\hline 260 & 220 & 700 & 0.07 & 0.03 \\
\hline 560 & 220 & 700 & 0.07 & 0.03 \\
\hline 860 & 220 & 700 & 0.07 & 0.03 \\
\hline
\end{tabular}

\section{Results and Discussion}

\subsection{Microstructure}

SLM parts under different heat treatment conditions were ground and polished to make the surface smooth and bright. Then, the random areas on the surfaces of the SLM parts (including asbuilt SLM parts and the SLM parts with different heat treatment temperatures) were observed under SEM and electron microscope, as shown in Figure 2. As shown in Figure 2 (a), the surfaces of the as-built SLM parts are almost uniformly distributed with reticular carbides. From previous studies, we can define that this special structure is mainly alloyed carbides, but the content of the alloying elements on the carbides is low. After heat treatment at $260^{\circ} \mathrm{C}$, the continuous network of carbides on the surface was cracked and distributed unevenly. The grain size also increased slightly. After heat treatment at $560^{\circ} \mathrm{C}$, the surface morphology of the SLM parts was restored to the surface morphology of the as-built SLM parts, showing a network structure again. Although the grains in the alloy returned to equiaxed grains after the heat treatment at $560^{\circ} \mathrm{C}$, the grain size was larger than those in the original SLM parts after the heat treatment. After the SLM sample was heattreated at $860^{\circ} \mathrm{C}$, a large number of granular carbides were precipitated on the surfaces of SLM parts. And these spherical particles were unevenly distributed on the surfaces, which proves the law of colloidal equilibrium, i.e., the metallic matrix dissolves small carbides particles and large carbides particles will grow. To further confirm the analysis results, an EDS energy spectrum analysis was carried out for the above-mentioned carbides. The results are shown in Table 3. 

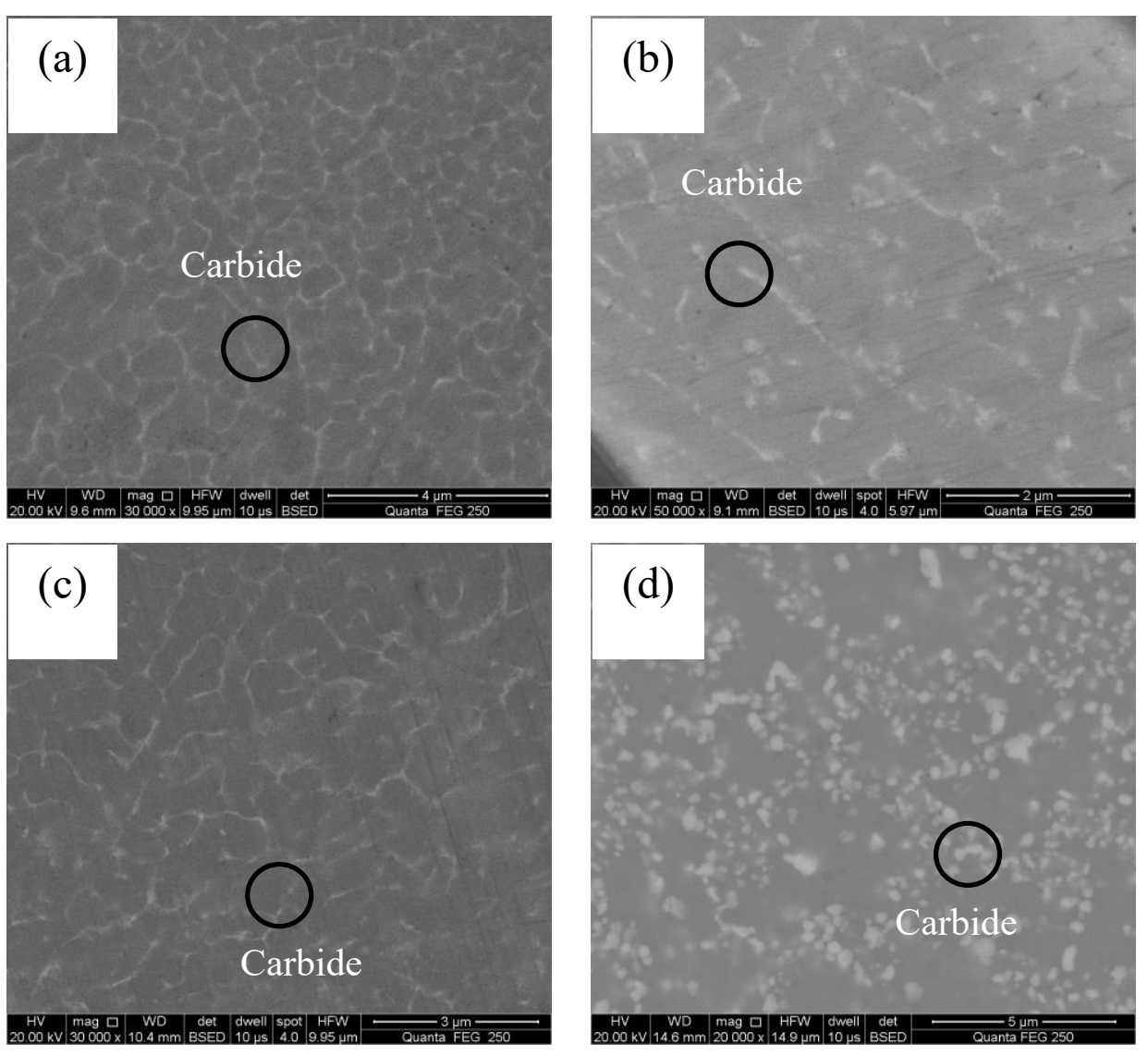

Fig. 2 SLM surface morphology at different heat treatment temperatures.

(a)As-built, (b) $260^{\circ} \mathrm{C}, \quad(\mathrm{c}) 560^{\circ} \mathrm{C},(\mathrm{d}) 860^{\circ} \mathrm{C}$

Table 3 EDS analysis of carbide in SLM sample after heat treatment of different temperatures

\begin{tabular}{ccccccc}
\hline Elements (wt. \%) & $\mathrm{C}$ & $\mathrm{W}$ & $\mathrm{Mo}$ & $\mathrm{Cr}$ & $\mathrm{V}$ & $\mathrm{Fe}$ \\
\hline As built & & & & & & \\
\hline After $260^{\circ} \mathrm{C}$ heat treatment & 4.27 & 5.45 & 3.46 & 3.85 & 1.93 & Remain \\
After $560^{\circ} \mathrm{C}$ heat treatment & 7.8 & 6.27 & 3.48 & 3.85 & 2.13 & Remain \\
After $860^{\circ} \mathrm{C}$ heat treatment & 1.41 & 12.24 & 5.93 & 4.45 & 2.61 & Remain \\
\hline
\end{tabular}

Generally, we know that rapid cooling promotes the transformation of austenite to martensite in HSS [11]. During the SLM process, the cooling rate is very fast. In this regard, there are lots of 
martensites in the as-built sample. However, the substrate keeps the sample at a specific temperature $\left(200^{\circ} \mathrm{C}\right)$. The sample is automatically tempered. A part of the martensite is decomposed, and the free carbon is combined with alloying elements in the matrix to form carbides. Finally, it precipitates at the grain boundaries and presents a network structure in the matrix. After heat treatment at $260^{\circ} \mathrm{C}$, martensite continues to decompose, the content of free carbon in the matrix increases. At this time, the carbide content in the matrix is saturated, and new carbides cannot be formed by combining the free carbon with more alloy elements. After heat treatment at $560{ }^{\circ} \mathrm{C}$, the martensite in the matrix is almost decomposed, and the free carbon is further increased. Moreover, as the temperature increases, the alloying elements (such as $\mathrm{W}, \mathrm{Mo}, \mathrm{Cr}, \mathrm{V}$ ) in the matrix combine with free carbon to form new alloying carbides. It precipitates again at the grain boundaries and presents a network structure in the matrix. After high-temperature heat treatment at $860^{\circ} \mathrm{C}$, the unstable carbides in the SLM samples were completely decomposed, eventually forming stable carbides (mainly W, Mo and V alloying carbides), which were distributed unevenly on the matrix in the form of spherical particles. The size of the carbides is large and coarse.

\subsection{Phase Analysis}

Figure 3 shows the XRD phase analysis of SLM samples at different heat treatment temperatures. According to the experimental results, although there is a large amount of residual austenitic (CFe15.1) in the as-built SLM parts, the surface carbides are evenly distributed on the grain boundaries, which plays a role of dispersion strengthening. As shown in the figure, in the SLM samples after the heat treatment at $260{ }^{\circ} \mathrm{C}$, part of the martensite is decomposed, which further increases the amount of residual austenite. At the same time, the decomposition of martensite leads to an increase in the amount of free carbon in the matrix and forms unstable $\varepsilon$ carbides, commonly referred to as carbide $\mathrm{CFe}_{2.4}$. When the heat treatment temperature was increased to $560{ }^{\circ} \mathrm{C}$, the residual martensite was completely decomposed, and the XRD pattern showed only three peaks of the $\alpha$-Fe phase. At the same time, alloy carbides precipitated again during the cooling process; it precipitated again at the grain boundaries and presented a network structure in the matrix. When the SLM formed parts were heat-treated at $860^{\circ} \mathrm{C}$, the amount of free carbon in the matrix increased, and it is easy to combine with alloy elements to form carbides. According to the XRD pattern, the carbides formed in the matrix are mainly $\mathrm{Fe}_{3} \mathrm{~W}_{3} \mathrm{C}$ carbides. These carbide aggregates grow and nodule according to the colloidal equilibrium law of small particle dissolution and the large particle growth. The carbides are unevenly distributed on the 
surface of the matrix, which weakens the strengthening effect of the carbides on the matrix and reduces the hardness of the SLM parts but improves the toughness of the part.

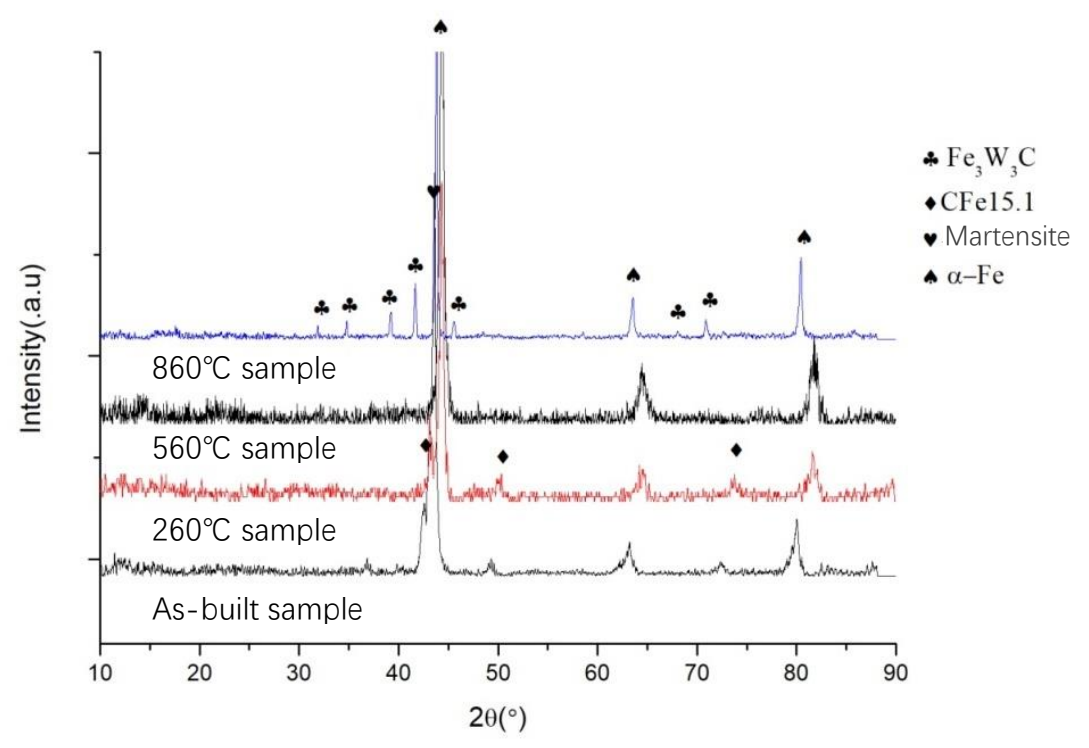

Fig. 3 XRD of SLM samples at different heat-treatment temperatures

\section{3 mechanical properties}

Table 4 lists the hardness values of the SLM parts at different heat treatment temperatures. The hardness of the as-built SLM parts is the highest. The average hardness values of the top and bottom surfaces are 61.8 HRC and 57.0 HRC, respectively. When the heat treatment temperatures are $260^{\circ} \mathrm{C}, 560^{\circ} \mathrm{C}$, and $860^{\circ} \mathrm{C}$, the hardness of the SLM parts decreases. The hardness value of the sample at $260^{\circ} \mathrm{C}$ decreases slightly. The average hardness values on the top and bottom surfaces are 58.9 $\mathrm{HRC}$ and 55.9 $\mathrm{HRC}$, respectively. After the heat treatment at $860^{\circ} \mathrm{C}$, the average hardness values of the top and bottom surfaces are 27.2 $\mathrm{HRC}$ and 26.9 $\mathrm{HRC}$, respectively. Although the hardness of the $860^{\circ} \mathrm{C}$ samples is lower than that of the as-built sample, the hardness values of the upper and lower surfaces of the $860^{\circ} \mathrm{C}$ samples are not much different. However, for the $560^{\circ} \mathrm{C}$ sample, the hardness value of the SLM sample is significantly different from that of the SLM samples at $260^{\circ} \mathrm{C}$ and $860^{\circ} \mathrm{C}$. At this point, the average hardness of the $560^{\circ} \mathrm{C}$ sample is very close to the hardness value of the as-built sample, and the average value is $61.5 \mathrm{HRC}$, and the hardness values of the upper and lower surfaces are also very close. It is similar to the hardness recovery phenomenon of tempering metallurgy of the HSS quenched powder.

From the above microstructure and elements analysis, we can conclude the reason for the 
hardness change after heat treatment at different temperatures. For the as-built SLM part, there are three primary strengthening mechanisms: fine crystal strengthening, dispersion strengthening and aging strengthening. First, at high cooling rates, the grain size of the as-built sample is too small, resulting in finer crystal enhancement. Also, since the substrate heats the sample during the SLM process, it causes the sample to self-temper. In this case, carbon atoms and alloying elements diffuse into the dislocations or other crystal defects areas, especially at the grain boundaries, and precipitate in the form of carbides. It makes the dislocations difficult to move and results in dispersion strengthening and aging strengthening. For the $260^{\circ} \mathrm{C}$ sample, a small amount of martensite in the structure was decomposed, the austenite content increased, and the carbide network structure was destroyed, broken into irregular shapes and distributed on the matrix, thereby weakening the strengthening effect. For the $560{ }^{\circ} \mathrm{C}$ samples, the martensite residue in the structure was transformed into tempered martensite, and a large number of free carbon was generated, carbides with alloy elements were formed and precipitated at the grain boundaries. This completes the secondary hardening, which increases the hardness. The most important thing is that the hardness of the upper and lower surfaces of the sample is the same. However, when the heat treatment temperature continued to rise to $860{ }^{\circ} \mathrm{C}$, the situation changed due to the slow cooling rate. The metal matrix is filled with cementite and soft ferrite, rather than harder martensite. According to the above XRD analysis, the main carbides in the matrix are $\mathrm{Fe}_{3} \mathrm{~W}_{3} \mathrm{C}$ carbide, and the aggregated carbides on the matrix grew up, weakening the dispersion strengthening effect.

Table 4 Hardness of SLM processed samples

\begin{tabular}{ccccc}
\hline Sample & \multicolumn{3}{c}{ HRC } & Average \\
\hline As-built top surface & $63.5,61.5,60.5,61.5,62.0$ & 61.8 \\
As-built lower surface & $58.5,57.5,57.0,56.5,55.5$ & 57.0 \\
$260^{\circ} \mathrm{C}$ Sample top surface & $59.5,60.5,58.5,58.5,57.5$ & 58.9 \\
$260^{\circ} \mathrm{C}$ Sample lower surface & $56.5,57.5,54.0,55.5,56.0$ & 55.9 \\
$560^{\circ} \mathrm{C}$ Sample top surface & $62.0,61.5,61.5,60.5,62.0$ & 61.5 \\
$560^{\circ} \mathrm{C}$ Sample lower surface & $59.5,60.5,62.0,60.0,59.5$ & 60.3 \\
$860^{\circ} \mathrm{C}$ Sample top surface & $27.0,27.5,30.0,26.0,25.5$ & 27.2 \\
$860^{\circ} \mathrm{C}$ Sample lower surface & $28.5,26.0,26.5,27.5,26.0$ & 26.9 \\
\hline
\end{tabular}


Table 5 shows the flexural strength of the SLM parts at different heat treatment temperatures. The average flexural strength of the as-built parts is $2417.33 \mathrm{MPa}$, which is higher than that of the traditional powder metallurgy M2 HSS (2100 MPa) [19]. However, the elongation of the SLM parts is low, and the fracture form is a mainly brittle fracture. After heat treatment, the tendency of the flexural strength of SLM parts is similar to that of the hardness change. After the heat treatment at $260^{\circ} \mathrm{C}$, the flexural strength of the sample decreased, and the elongation increased. After heat treatment at $560^{\circ} \mathrm{C}$, the flexural strength of the sample is the same as that of the as-built part. However, the elongation of the $560^{\circ} \mathrm{C}$ specimen is higher than that of the as-built sample. For the $860^{\circ} \mathrm{C}$ samples, the flexural strength of the part exceeded that of the as-built sample, and the elongation reached its peak.

Table 5 Flexural strength of SLM processed samples

\begin{tabular}{ccccc}
\hline Sample & Flexural strength (MPa) & Average & Elongation $(\%)$ & Average \\
\hline As-built Sample & 2450, 2387, 2415 & 2417.33 & $2.72,2.69,2.53$ & 2.65 \\
$260^{\circ} \mathrm{C}$ Samples & $2132,2224,2197$ & 2184.33 & $3.10,3.27,3.15$ & 3.17 \\
$560^{\circ} \mathrm{C}$ Samples & $2420,2408,2392$ & 2406.67 & $2.93,2.87,2.94$ & 2.91 \\
$860^{\circ} \mathrm{C}$ Samples & $2450,2412,2439$ & 2433.67 & $6.75,6.83,6.71$ & 6.76 \\
\hline
\end{tabular}

The as-built parts have a high flexural strength but a low elongation. It shows obvious brittle fracture characteristics. The fracture characteristics of the SLM parts changed after heat treatment at different temperatures. Fig. 4 shows the SEM fracture morphology of the SLM parts before and after heat treatment at different temperatures.

Flexural strength is the ability of a material to resist bending without breaking under external forces. This mechanical property is related to the grain size, the morphology and distribution of carbides, and the preferred texture in the microstructure. It can be found from the fracture morphology diagram shown in Fig. 4 that the as-built part has a large number of cleavage steps, and deformed columnar-crystal structures appear in the fracture area. We can observe that the cleavage steps are large, which is a typical brittle fracture. When the SLM parts were heat-treated at $260^{\circ} \mathrm{C}$, the flexural strength decreased, and the number of cleavage steps and the deformed 
columnar crystal structure were significantly reduced. After heat treatment at $560^{\circ} \mathrm{C}$, no apparent columnar crystal structure was found in the fracture structure, but there was still a small amount of cleavage steps on the surface, and the fracture form was a brittle fracture. For the $860^{\circ} \mathrm{C}$ samples, the flexural strength of the SLM parts also reached and exceeded that of the original SLM parts. At this point, a large number of dimples were observed in the cracks, but the size and distribution of the dimples were uneven.

The as-built SLM parts are dense, so there are no pores in the structure. The sample has fine grains and solid solutions of alloying elements, both strengthen the metal matrix. Besides, the SLM process has different scanning directions for each layer, which makes the SLM part form a scanning braid structure and dramatically increases the strength of the forming section. However, from the above-mentioned experimental analysis, it can be known that the carbides in the SLM part are distributed at the grain boundaries as a network structure, and a large number of preferred columnar crystal structures are distributed in the lower part of the SLM sample. This structure significantly reduces the plastic deformation ability of the sample. Therefore, the fracture form of the as-built sample is a mainly brittle fracture. For the $260^{\circ} \mathrm{C}$ samples, some martensite in the SLM samples decomposed, and the overall strength decreased. Carbides precipitate and are unevenly distributed at the grain boundaries, resulting in reduced flexural strength of the SLM parts. However, the overall structure is more uniform than that of the as-built samples, and the number of columnar crystals is decreased, which improves the anisotropy of the samples. When the heat treatment temperature reached $560^{\circ} \mathrm{C}$, the quenched martensite in the SLM parts was transformed into tempered martensite, and the various carbides formed were dispersed in the matrix, which again increased the strength of the matrix and restored the flexural strength. At this point, the carbides were redistributed in the grain boundaries in a network structure, which increased the brittleness of the SLM sample. When the heat treatment temperature was $860^{\circ} \mathrm{C}$, although the grains in the SLM part was coarse and the carbides were agglomerated and distributed on the surface of the matrix in the granular form, the brittleness caused by the initial distribution of brittle carbides at the grain boundaries is increased. At the same time, the overall performance of $\mathrm{Fe}_{3} \mathrm{~W}_{3} \mathrm{C}$ carbides are excellent, and the toughness of the SLM samples is increased. Therefore, the flexural strength of the $860^{\circ} \mathrm{C}$ samples exceeds that of the original SLM samples, and the fracture mode is a ductile-brittle composite fracture. 

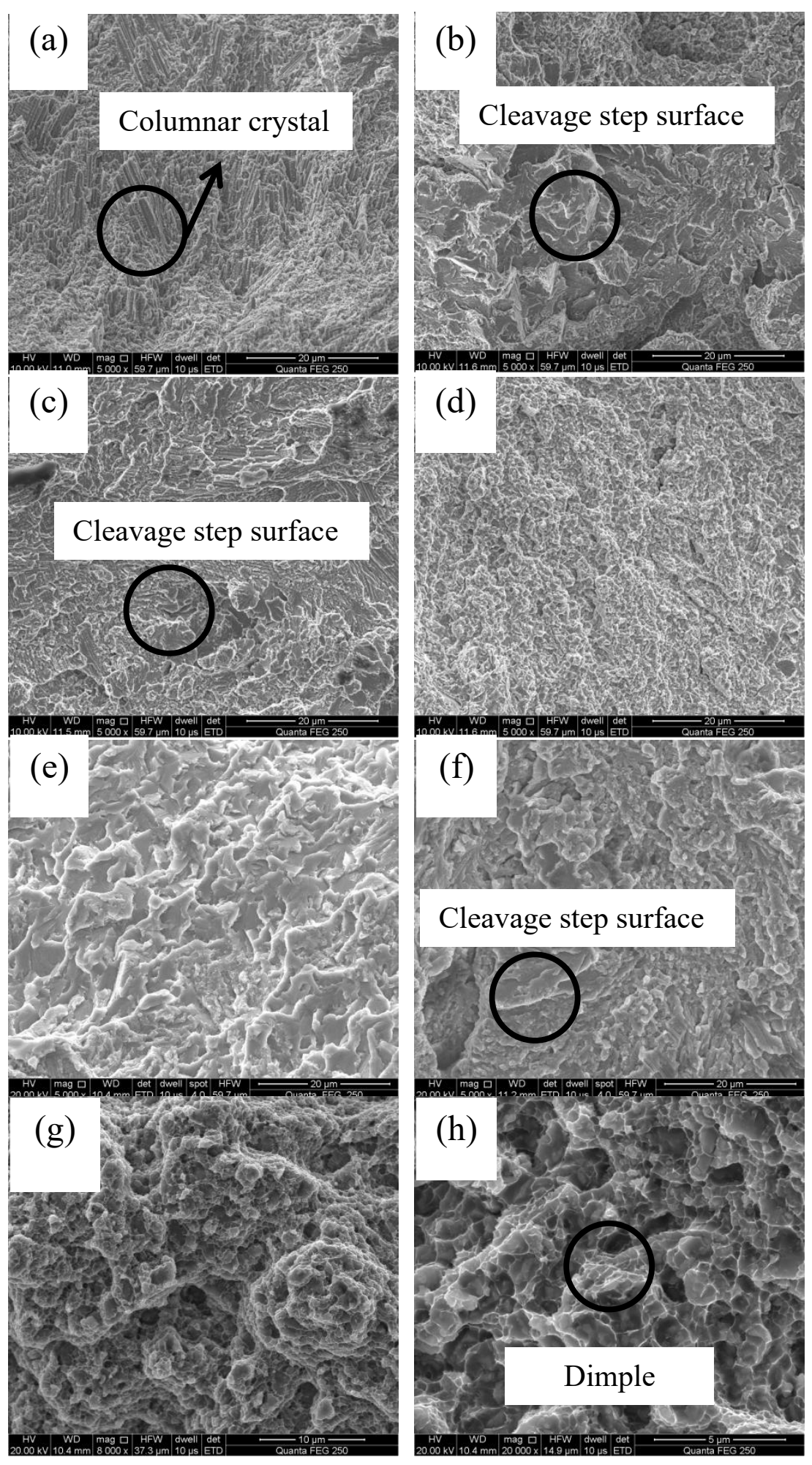

Fig. 4 SEM fracture morphology of SLM samples

(a-b)As-built, (c-d)After $260^{\circ} \mathrm{C}$ heat treatment, (e-f)After $560^{\circ} \mathrm{C}$ heat treatment, (g-h)After $860^{\circ} \mathrm{C}$ heat treatment 


\section{Conclusions}

In this paper, the effects of heat treatment temperature on the density and properties of the M2 HSS parts by the SLM process were studied. The conclusions are summarized as follows:

- At different heat treatment temperatures, the hardness and flexural strength of the SLM parts show mixed trends. When the subsequent heat treatment temperatures were $260^{\circ} \mathrm{C}$ and $860^{\circ} \mathrm{C}$, respectively, the hardness and flexural strength of the SLM molded parts decreased. At $860^{\circ} \mathrm{C}$, the hardness of the SLM molded parts reached the lowest, with an average value of $24 \mathrm{HRC}$, and the microstructure of the sample was uniform. When the subsequent heat treatment temperature was $560^{\circ} \mathrm{C}$, the hardness and flexural strength of the SLM molded parts were very close to that of the original SLM molded parts, and the performance anisotropy of the samples was improved, and the overall structure is uniform without apparent preferred direction.

- After heat treatment at $860^{\circ} \mathrm{C}$, the fracture mode of the SLM parts is transformed into a ductile-brittle composite fracture. Although the hardness is greatly decreased, the flexural strength is significantly increased. Subsequent heat treatment can improve the toughness performance of the SLM parts to a certain extent, but the heat treatment temperature is required to be higher than $860^{\circ} \mathrm{C}$.

\section{Acknowledgments :}

The current work is supported by Central South University. The project belongs to the National key research and development program funding projects, and the number is 2016YFB0700302. The authors would like to express their gratitude to EditSprings (https://www.editsprings.com/) for the expert linguistic services provided.

\section{References}

[1] ZHANG Ying. SLM technology impact on mold manufacturing and its technology development [J]. Big Technology, 2016(9):218-218.

[2] KRUTH J P, FROYEN L, VAERENBERGH J V, et al. Selective laser melting of iron-based powder [J]. Journal of Materials Processing Tech, 2004, 149(1): 616-622. 
[3] WANG Li. Study on the performance of selective laser melting metal parts [D]. Wuhan: Huazhong University of Science and Technology, 2012.

[4] MERTENS R, VRANCKEN B, HOLMSTOCK N, et al. Influence of powder bed preheating on microstructure and mechanical properties of H13 tool steel SLM parts[J]. Physics Procedia, 2016(83): 882-890.

[5] HOEGES S, ZWIREN A, SCHADE C. Additive manufacturing using water atomized steel powders [J]. Metal Powder Report, 2017, 72(2): 111-117.

[6] FRANCESCO T. Effects of heat treatments on A357 alloy produced by selective laser melting[C]// WEISSGAERBER T, Thomas Weissgaerber, Rapid. Tech-International Trade Show \& Conference for Additive Manufacturing. Germany, European Powder Metallurgy Association, 2016: 1-6.

[7] FORÊT P, BAUER D. Effect of process gas and powder on AlSiMg powder bed fusion processed parts for the six aerospace industry[C]// ITURRIZA I. Iñigo Iturriza, Rapid. TechInternational Trade Show \&-Conference for Additive Manufacturing. Germany, European Powder Metallurgy Association, 2016: 1-6.

[8] FRISK K. Characterisation of EBM-Built Shelled Samples of Ti6Al4V Compacted by HIP $[C] / /$ KIEBACK B. Bernd Kieback, Rapid. Tech-International Trade Show \&-Conference for Additive Manufacturing. Germany, European Powder Metallurgy Association, 2016: 1-6.

[9] WANG Xiaolong. Optimization and performance study on the melting process of titanium alloy laser [D]. Guangzhou: South China University of Technology, 2016.

[10] TONG Shiwei. Preparation and performance of M2 powder metallurgy high-speed steel [D]. Xiangtan: Xiangtan University, 2016.

[11] ZHOU Xuefeng, FANG Feng, JIANG Jianqing. Effect of cooling rate on $\mathrm{M}_{2} \mathrm{C}$ eutectic carbide of high-speed steel [J]. Foundry, 2008, 57(7): 658-660.

[12] CHI Hongxiao, MA Dangcan, WU Lizhi. Phase transformation behavior of M2C eutectic carbide in M2 high-speed steel [J]. Metal Heat Treatment, 2010, 35(5): 19-22.

[13] CHEN Shunmin, ZHANG Qing, ZHU Xinfa. Characteristics, heat treatment technology and application of powder metallurgy high-speed steel [J]. Heat Treatment, 2008, 23(2): 14-16.

[14] ZHOU Rui, SUN Guifang. The influence of sintering temperature on the structure and properties of M3:2 high-speed steel SPS [J]. Hot Working Process, 2013, 42(12): 54-57. 
[15] WEN Xiaohao, CHEN Sheng, DING Xiaoqin, et al. Microstructure and properties of SPS sintered M42 powder metallurgy high-speed steel [J]. Powder Metallurgy Technology, 2010, 28(1): 39-42.

[16] Geenen, Karina, et al. Microstructure, mechanical, and tribological properties of M3: 2 highspeed steel processed by selective laser melting, hot-isostatic pressing, and casting [J]. Additive Manufacturing, 2019,28: 585-599.

[17] DING Huan, XIONG Xiang, et al. Effects of substrate temperature on Microstructure and Property of M2 High-Speed Steel prepared by Selective Laser Melting [J]. Materials Science and Engineering of Powder Metallurgy, 2018, 23(05): 511-517.

[18] LUO Tao, JIANG Wenqin, TONG Wei. Powder metallurgy preparation and Microstructure and properties of M2 High-speed steel [J]. Powder Metallurgy Industry, 2019, 29(06): 28-33. 